\title{
Learning English through Active Participation (LEAP)
}

\author{
Dr. Siva Mahendran
}

(Associate Trainer, TVI) in association with Centre for Educational Leadership, Training Vision Institute, Singapore.

\section{INTRODUCTION}

The teaching of English and workplace literacy skills can be dry and often very uneventful for the learners and it takes a resourceful, reflective and proactive trainer / teacher to align lessons to match the competency levels of the learners, their aspirations and also their keenness to learn. Traditional and even blended learning have seen run of the mill teaching and learning strategies till now and there is a need to fill the gaps left behind by these approaches to further ignite the passion in learners, to learn with a fire to assimilate and enrich themselves even more in their learning journey. This is not to say we need to replace the present teaching / training styles but to infuse more meat into the learning process to make it much more a fun activity than a tedious 'get-it-over-with' experience for all in the language learning environment wherever it may be.

\section{BACKGROUND}

With the recent introduction of blended learning and the use of various applications like Blackboard, TVI app, Nearpod, English Central, etc. the teaching and learning of workplace English has seen a paradigm shift away from the traditional talk and chalk, or rather the marker pen and whiteboard way of conducting lessons in the classroom. Then there was the introduction of multimedia including mobile phones and tablets to spice up the lessons even more but these have somewhat lost their original glamour in attracting and getting learners to do their learning not only in the classroom but also in the comfort of their homes to revise lessons learnt or to do homework given to reinforce their learning even more. More often than not, these have become more of an artificial and superficial way of getting lessons to be taught and learnt using not just textbooks (which is going out of vogue) but also the use of information technology and the internet of things to get learning done more expeditiously and with a difference, to assimilate as much knowledge and practice as possible, supposedly with much passion and diligence, but without much consideration to believe that there was 'fun' in doing so. This is a cause for concern in teaching and learning a language like English which can be tough for most learners who are so used to their vernacular means of communication with little exposure to use the lingua franca with others comfortably. Often learners are pre-judged and feel marginalised in the classroom when the more eloquent and vocal adult learners take the limelight from the rest who may sit passively and seem involved but in fact may be unmotivated to learn with fervour even more through the course of learning. Some learners may also lose their original motivation to learn over time if they find the lessons dry and run of the mill at every lesson over time. This does not bode well to the learning and practice of English language skills as without actively participating in the lessons, learners may mentally 'switch off' and lose 'steam' whilst they are in the course of learning.

Objective: To create fun through gamification and using nostalgic childhood leisure activities in order to motivate learners in the Workplace Literacy Program in learning English.

\section{BENEFITS AND FEASIBILITY}

LEAP would benefit the teaching and learning processes as it rekindles even the passive learners to get involved in a fun way to learn and practice language skills even more through the now much unused, and often neglected use of, childhood and age-old traditional games and socio-cultural shared experiences which would also be a game-changer in getting the learners to learn in a more collaborative mode with any learner rather than gravitating to their own racial and cultural groups in the classroom. Language skills like vocabulary, word formations, reading, speaking, listening and writing could be further enhanced over a shorter time rather than relying on the IT-infused blended way of learning presently done.

There is much scope in the use of traditional games and socio-cultural shared experiences in learning a language for adults in the workplace literacy program and it adds to the blended learning that is often associated with the internet and the infusion of IT in the classroom. There is greater variety in learning a language with the use of games and 
traditional socio-cultural shared experiences and learning. Time would be more efficiently and effectively used with total class participation rather than having a few or more being uninvolved or passive learners.

\section{Gamification*}

Some elements of games that may be used to motivate learners and facilitate learning include:

- $\quad$ Progress mechanics (points/badges/leaderboards, or PBL's )

- $\quad$ Narrative and characters

- Player control

- Immediate feedback

- Opportunities for collaborative problem solving

- Scaffolded learning with increasing challenges

- Opportunities for mastery, and leveling up

- Social connection

$*$

Source:

https://en.wikipedia.org/wiki/Gamification of learning

\section{DESCRIPTION OF LEAP}

Learning English through Active Participation requires the trainer to be actively involved in facilitating active learning especially during the warm-up, introduction, evaluation and application stages of the lesson following closely with the WIPPEA strategy in the Workplace Literacy Program of WDA, MOM, which has been in force since 2005 (https://www.casas.org/about-casas). The language lesson could be infused with donated or trainer prepared materials for learning which could be thematic, add-ons or applications of concepts learnt via the trainer's own creativity and level of involvement towards excellence in teaching.

The following could be infused into lessons in a thematic mode or as enrichment matter to add value to motivate and spice-up language lessons even more:

- $\quad$ songs and nursery rhymes

- poems

- famous sayings and proverbs

- famous speeches (eg. Martin Luther King's or Lee Kuan Yew's )

- jokes and riddles
- traditional childhood games - monopoly, snakes and ladders, card games like Snap, Happy Families, UNO, Scrabble, Upwords etc.

- comic strips and cartoons

- childhood stories - Three little pigs, Snow White and the Seven Dwarfs, Cinderella, parables from Aesop's fables eg. Rabbit and Tortoise race, sour grapes, the lion and the mouse, the crow and the water pitcher, etc.

- $\quad$ word puzzles and quizzes

- debates and forums (taboo-topics like race, politics and religion excluded)

- Charades

- Dramatisation and role playing

- Mini-karaoke sessions (use of mobile phones and texts)

- Storyboards and story-telling sessions (donated books and sharing own experiences)

- Jig saw puzzles

- Lego puzzles

- Etc.

Sample Lesson using the LEAP approach

Workplace Literacy Program (Level 4) - Conversational Unit 1- Conversing with Confidence

Warm-up - Playing a word puzzle - working in pairs to uncover scrambled words and phrases on greetings and introductions. (About 10 mins)

Evaluation - Filling in the blanks activity sheets on the type of greetings to be given and the response to the greetings in a role play which could later be spoken in pairs. Happy Family game could be played with use of greetings with asking for a card with the name of a person to get a family set of cards; eg. "Hello, may I have Miss Pots please?" or "Good morning, may I know if Mr Gardener is in?"(10-15 mins)

\section{APPLICATION}

Work in pairs or groups to fit phrases and words to fill in the blanks or match words and phrases in order to create sentences before doing a role-play or dramatising the finished conversations (10-15 mins)

Theories that LEAP teaching approach encompasses: 
i. $\quad$ Oral Approach and Situational Language Teaching (Hornby,A.S.,1950)

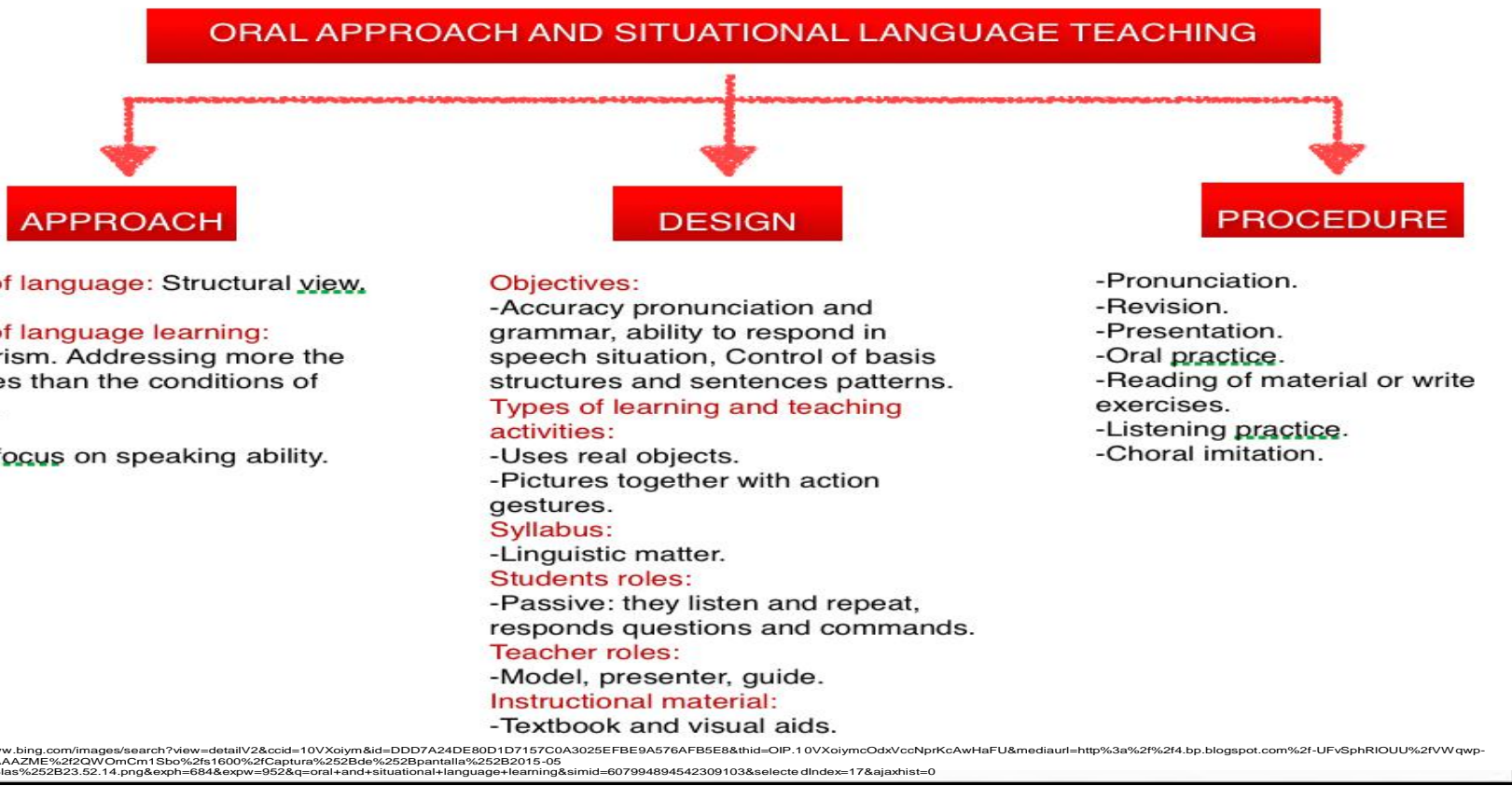

ii. $\quad$ Communicative Language Teaching (CLT) approach, (Brumfit, C.J. \& Johnson, K., 1979) widely used from mid-1970s to the 1980 s period,

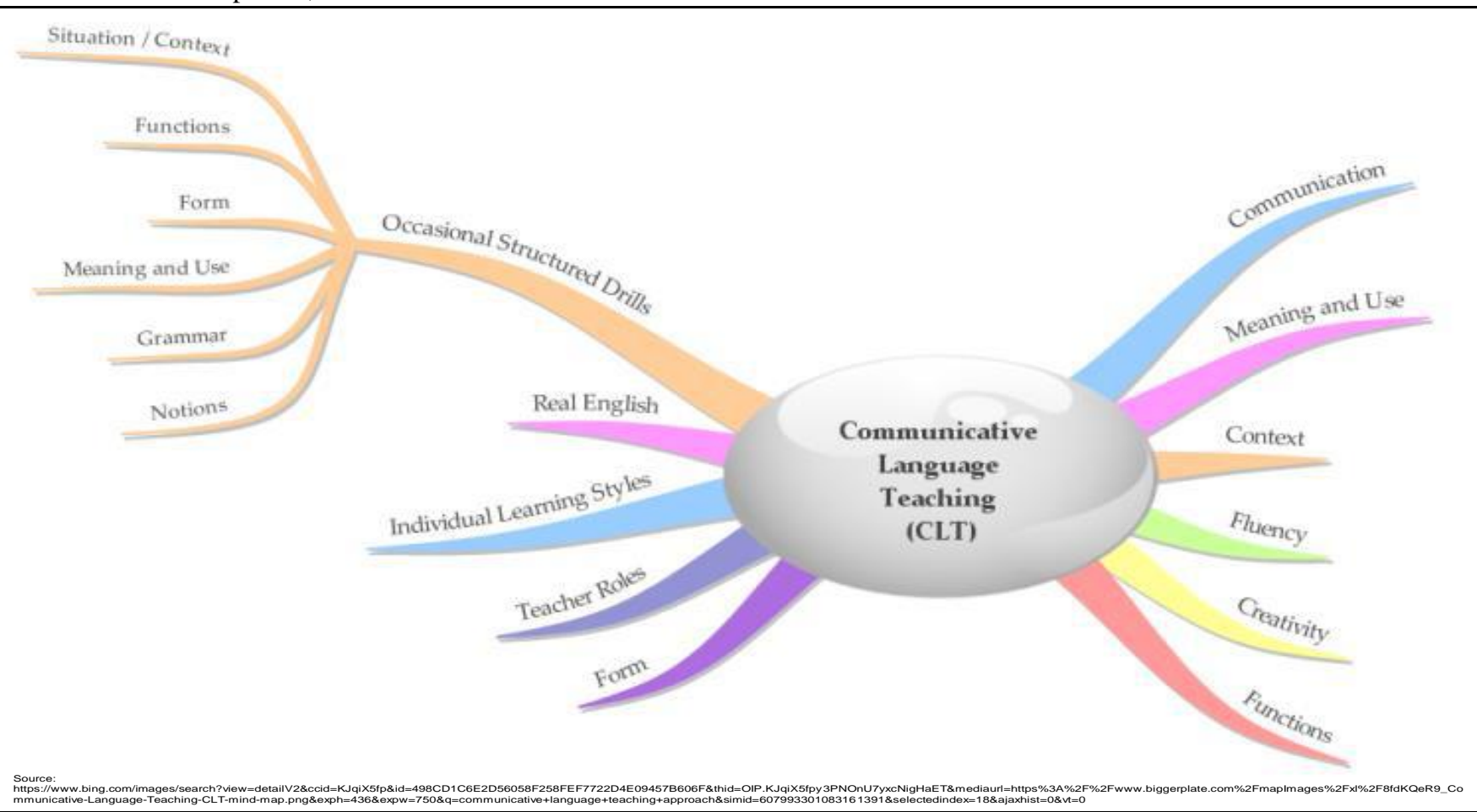


iii. Task-based Language Teaching (TBLT) approach (Foster,P. \& Skehan,P., 1996)

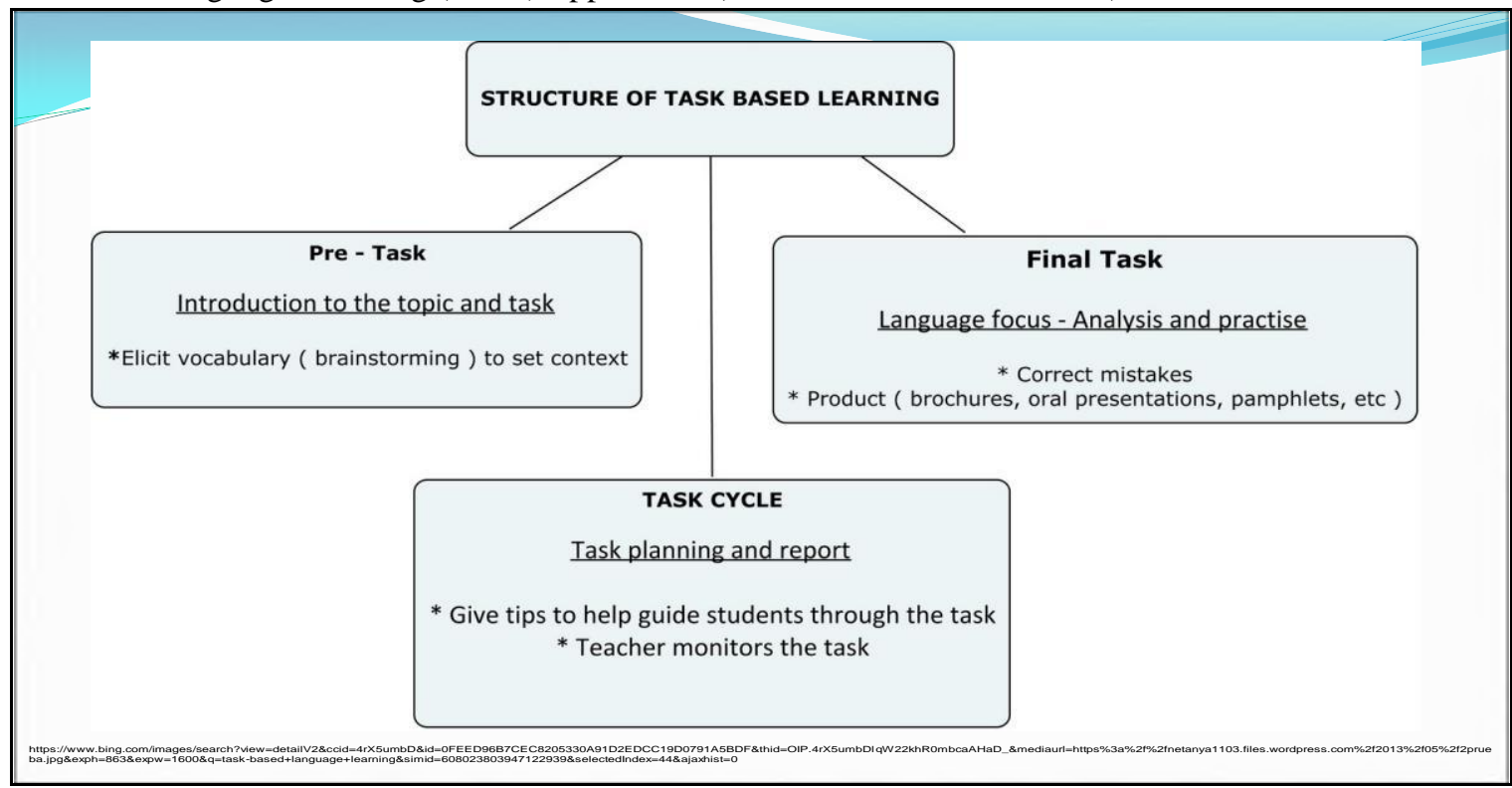

\section{CHARACTERISTICS OF ADULT LEARNERS}

\section{Knowles (1970) mentioned six principles of adult learning.}

Adult learners:

are basically self -directed and internally motivated

have life-experiences

have knowledge of learning experiences (being reflective learners)

are goal and relevancy -oriented

are practical

like to be respected.

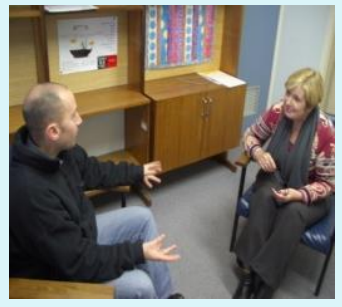

Knowles, M. S. (1970). The Modern Practice of Adult Education. Andragogy versus pedagogy, Englewood Cliffs: Prentice Hall/Cambridge

\section{Schedule}

Once the project has been approved, to create activities for each level of the workplace literacy level, it would probably take a month or so to complete having to source for the materials and doing up the instructions for the activities in the program for all the lessons and preparing the TTT to disseminate the instructions at meetings. The total time could take up to 3 months to be completed.

\section{Cost and Required Resources}

Costs could be kept to a minimum and would only include procurement of games sets and story books as most could be donated by trainers, learners, the public, well-wishes and even philanthropists in a concerted drive by the organisation at public events, advertisements, in classes at the various training centres etc. Materials and story books could also be purchased in second-hand shops and from self-help groups like the Community Chest and from clearance sales from the National Library etc.

\section{CONCLUSION}

A few dry runs of the project in the different levels of the WPL program could be done in the interim to assess its 
effectiveness and qualitative surveys (social media, questionnaires, interviews, etc.) could be done to ascertain the usefulness and the satisfaction levels of learners in LEAP's initial experimentation prior to its implementation. It is hoped that the results would speak for themselves as learners being more motivated to learn English could get better post-test scores.

\section{REFERENCES}

[1] Brumfit, C.J. \& Johnson, K. (eds). (1979) . The Communicative Approach to Language Teaching. Oxford: Oxford University Press.

[2] Foster,P. \& Skehan,P. (1996). The influence of planning and performance in task-based learning. Studies in Second Language Acquisition. 18: 299-324.

[3] Hornby, A.S. (1950). The situational approach in language teaching. A series of three articles in English Language Teaching. 4:98-104,121-128,150-156.

[4] Knowles, M. S. (1970).The Modern Practice of Adult Education. Andragogy versus pedagogy, Englewood Cliffs: Prentice Hall/Cambridge. 